\title{
Analogue Angels and Digital Diamonds: Tracing the Origins of New Media Art
}

\author{
John Charles Ryan \\ Edith Cowan University
}

\begin{abstract}
This paper explores the key vocabularies, themes, ideas, artistic movements, and technological innovations contributing to the development of the digital arts over time. As new media theorists have argued, one of the defining features of the digital arts is the break-down of divisions between art forms, and between art and society (for example, Manovich 2001, 2005). This paper outlines how digital processes intersect with aesthetic and conceptual forms. Relevant frameworks, such as materiality, embodiment, hybridity, interactivity, and narrativity, form the origins of the genre. Digital artworks, like digital media, are interactive, participatory, dynamic, and customizable, incorporating shifting data flows and real-time user inputs (Paul 2003, 67). The customization of content and technology, as well as the recontextualization of information, characterize projects of digital art.
\end{abstract}

Keywords: digital, new media, art, culture

\section{Introduction: The Analogue and the Digital in Art}

This section briefly outlines concepts of materiality, embodiment, cyborg, hybridity, interactivity, narrative, and interface. Among these terms, there are considerable interconnections and commonalities. For instance, materiality necessarily involves the notion of embodiment; the cyborg reflects the concept of hybridity; and an interface makes interactivity possible. This section also probes the essential conceptual distinction between digital arts as a "tool" and a "medium" (Paul 2003). The digital arts differ from "analogue," traditional or pre-digital art forms, broadly including painting, sculpture, film-based photography, ink-based printmaking, sound recordings on vinyl records, and writing done on a typewriter rather than a computer. Within the category of analogue art, most writers differentiate between the fine arts and the fiber arts (Janson 2004, 17). Both kinds of art make use of tangible, physical materials (e.g., canvas, paint, film, ink, vinyl, steel, wood, and stone) and are created by hand or with non-computerised instruments. As indicated by the range of analogue practices recognised as art, historians over time have expanded the field of art to accommodate emerging forms and mediums. (Note that "analogue" also refers to an early form of technology, explored later in this paper). The label "fine arts" typically refers to sculpture and architecture, as well as painting, illustration, drawing, printmaking, silk-screen printing, bindery, and other graphic art forms printed on paper. Additionally, throughout the history of art, stained glass and illuminated manuscripts have been considered as forms of painting and, therefore, classified as fine art, whereas photography has been more recently admitted. In contrast, the term "fiber arts" includes textiles, metal-smithing, ceramics, glasswork, beadwork, and other productions in

John Charles Ryan, postdoctoral research fellow, School of Communications and Arts, Edith Cowan University, Australia; main research field: Digital Art. Email: john.ryan@ecu.edu.au. 
mixed mediums (Janson 2004, 17).

It is important here to consider the various ways the terms "medium" and "media" are used. In the context of fine and fiber arts, a medium refers to the material from which the artwork is made. However, in terms of the digital arts, this paper uses "media" to refer to "new" and "social" media, such as the internet, Facebook, Youtube, mobile phones, and other technologies that allow immediate access and contribution of content in the form of digital images, video, and text. Moreover, "multimedia” usually describes works mixing text, audio (music or voice), static images (scanned images or computer graphics), and moving images (video, cinema, or computer animation) (Wilson 1993). Historically, the term "multimedia" referred to slide shows accompanied by audio (Wilson 1993). More recently, the term "hypermedia" refers to an interactive, non-linear structure enabling viewers to select unique trajectories through information (Wilson 1993).

\subsection{Digitality}

There are different ways an artwork comes to be categorized as digital. Consider a photograph of a mountain taken with an analogue camera, developed in a lab using traditional film development processes, and then scanned and manipulated with digital tools, such as Adobe Photoshop. In contrast, think about a photograph of the same mountain taken in a digital medium, then printed to paper appearing identical to the analogue version of the work. Referring to this difference, theorists of media art distinguish between a "tool" and a "medium" in characterizing the use of digital technologies by artists (Lovejoy, Paul, \& Vesna 2011, 7). As a tool, a technology facilitates the creation of a traditional artwork—a sculpture, painting, or dance —or makes possible the conversion of an analogue work to digital format to enhance its distribution, storage, or long-term preservation. Digital technologies applied as tools in the production of art may include, for example, digital photography and imaging. Indeed, artists working in different media-including painting, drawing, sculpture, photography, and video—-make use of digital technologies as a tool (Paul 2003, 27).

Digital tools make possible an array of techniques for manipulating an artwork, resulting in the synthesis of art forms and the integration of media as separate as photography, film, and video (Paul 2003, 27). Other outcomes of the use of digital tools include the recontextualization of an original artwork through the techniques of collage or appropriation, as well as the general blurring of the relationship between a copy and the original (Paul 2003, 27). For example, a painting is digitized and uploaded to a gallery's website for online distribution or a dance is recorded digitally and burned to a DVD or broadcast on YouTube. In contrast, as a medium, a technology intrinsically underlies an artwork's production, preservation, and distribution. As a result, the work engages in a significant way with the medium's interactive, dynamic, participatory, and customizable possibilities (Lovejoy, et al., 2011, 7). Digital technologies applied as mediums may include installation, music, sound, film, video, animation, internet art, software art, and works based on virtual reality. Works that employ digital technologies as a medium range from browser-based internet projects to interactive installations combining telerobotics and webcams.

\subsection{Materiality}

Materiality is a core theoretical term for the digital arts and, in many ways, relates to the above discussion of the differences between analogue and digital, and tools and mediums. Broadly defined, "materiality" connotes the physical qualities of an object, artefact, substance, living body, or artistic work. For instance, a common tool, such as a modern hammer, can be defined by a set of properties: the hard steel of the head, the 
fibreglass of the handle, and the pliant rubber covering the fibreglass and providing a surface for the human hand to grip (Leonardi 2012, 28). In traditional (that is, analogue) art terms, materiality is a property of the medium of an artwork. Mediums like stone, wood, or paint all possess a suite of specific material qualities - hardness, malleability or viscosity, amongst others that make them appealing to artists and appropriate for creating particular kinds of works. At a broader level, materiality signifies the larger physical world with which an artist engages or from which the artwork is generated. For example, site-specific productions, such as Andy Goldsworthy's Sheepfolds (1996-2003), intrinsically reflect the materiality of places - a field, mountain, or riverine environment, as well as the interplay of elements, weather, seasons, flora and fauna, and seasons that constitute the place.

While the materiality of an artwork is definable, it is not fixed. Instead, materiality consists of the ever-changing matter (material) and form (structure) of a physical or digital work. While the physical properties of the tangible world are obviously vital for artists and their works, the term "materiality" is neither synonymous with "physicality," nor does it merely designate the materials employed to produce an artwork. That materiality is both matter and form which are of significance for digital artists and writers attempting to describe digital artworks—such as internet browser art—which can be extremely variable over time, often consisting of little or no physical matter (e.g., no stone, wood, or paint, but rather electrons on a screen manipulated by the user's mouse and keyboard). Moreover, materiality is the lasting aspect of a work. As theorist Paul Leonardi reminds us, "when we say that we are focusing on a technology's materiality, we are referring to the ways that its physical and/or digital materials are arranged into particular forms that endure across differences in place and time” (Leonardi 2012, 29).

Furthermore, art historians refer to "materialization" as a process whereby a concept becomes matter and takes form. For example, the artisanry of a craftsperson manifests (or materializes) the hammer. In the same way, the participation of a viewer in a browser-based artwork materializes the work's form before that form is transformed by another user. Indeed, the materialization in the artwork of a participant's intention can increase and sustain viewer involvement over time (Stiles \& Shanken 2011, 45)—a condition of central importance to many open-ended, interactive artworks without fixed endings or physical parameters. On a comparable note, numerous digital artworks confront the material conditions of the human body in relation to the digital interfaces (e.g., screens, browsers, email portals) through which our bodies connect to technologies and, thus, interact with the works, leading to considerations of the role of the human body in a gradually more technological world (Paul 2011, 111).

\subsection{Embodiment}

The term "embodiment" describes a condition of being in the world in which the mind and the body are not constructed as separate or independent entities. In contrast, the mind/body split is attributed to the French philosopher René Descartes (1596-1650) whose famous assertion "Cogito ergo sum” or "I think therefore I am" paves the way for Cartesianism as the doctrine of logic and reason (the mind) over intuition and the senses (the body). The philosophy of embodiment contends that the mind and the body intertwine-reciprocally modifying one another as human beings experience, affect, and are shaped by the world around us. In close relation to notions of materiality explained previously, embodiment points to the vital interactions between a subject and an environment (living or non-living), leading to certain human behavioral patterns and mental states (Scott \& Bisig 2011, 306). In other words, rather than "I think therefore I am," the philosophy of embodiment revises 
Descartes' famous yet problematic aphorism to "I am immersed in the world therefore I am.”

The Australian performance artist Stelarc, whose works deal at length with notions of embodiment, comments that "when I talk about the body, I mean this cerebral, phenomenological, aware, and operational entity immersed in the world. Not only should we not split mind and body; we should not split the agent from its environment” (Stelarc \& Smith 2005, 216). For digital artists, artworks, and “agents” (e.g., viewers, users, participants, technologies, or other living or non-living objects immersed in the work and contributing to its development), the notion of embodiment also calls attention to the incorporation of technological devices into human bodies. This intimate role of technology relates to concepts of the "cyborg" (a "cybernetic organism" possessing natural and artificial parts) and human-machine interdependence in the digital era. In fact, the theme of embodiment across various forms of digital art encompasses questions about broader human relationships to virtual and physical spaces (Paul 2003, 165), particularly those associated with emerging technologies like computer-simulated virtual reality (VR).

\subsection{The Cyborg}

The cyborg as a cybernetic organism is a metaphor for human-machine hybridity. In the 1940s, American mathematician Norbert Wiener (1894-1964) proposed the science of cybernetics as the comparative study of communication systems among humans, other organisms, and machines. His book Cybernetics: Or Control and Communication in the Animal and the Machine (originally published in 1948) argues that "feedback" provides a crucial way to understand how humans and other living beings adjust to their surroundings (Wiener 1961). Weiner uses the analogy of a steersman controlling a board to navigate a turbulent river to demonstrate the link between control and communication. His writings impart a new technical significance to communication and language through a mathematical basis, triggering a shift from the Newtonian model of the universe based on energy and matter to one based on information flows and embodiment (Mitra \& Bokil 2008, 7-8). The cyborgian metaphor of "man-machine symbiosis" is explored by a number of contemporary digital artists (Paul 2003, 9), including Stelarc and bioartist Eduardo Kac. Moreover, the concept of the cyborg—as a modern form of human embodiment that integrates machines-underscores the relationship between identity and digital technologies. How should we understand ourselves and our globalised world in reference to a number of opposing contexts: real and virtual, animate and inanimate, human and machine (Lovejoy 2004, 241)?

Californian media artist Victoria Vesna's work interrogates notions of information flows and embodiment in digital environments. Developed in conjunction with musicians and programmers, Bodies INCorporated (1996) (www.bodiesinc.ucla.edu) is a website that enables users to create a "cyberbody” (Paul 2003, 168). The project's avatar-a spinning golden head with a copyright symbol emblazoned on its forehead-welcomes visitors to the website. Web viewers become immersed in a parody of a corporate structure (Kac 2005, 94). Clicking on the logo, you find the conditions of use and, before proceeding, must agree to the "legalese" embedded in "restrictions on use of materials," "termination," "disclaimer," and "limitation of liability." Further inside the artwork, you are invited to build bodies — which "become your personal property, operating in and circulating through public space, free to be downloaded into your private hard drive/communication system at any time" (Bodies INCorporated, n.d.). You choose a body to wander in through different spaces including the "gated community" known as "home" or "limbo" where "immaterialized thought-forms are detained until final judgment” and the "dark and foreboding, yet oddly inviting Necropolis.” More disturbingly, you can decide to kill off your body and replace it with another. The spinning avatar head reminds us of the 
rejection of the human body's central role in the world by the Cartesian philosophy of knowledge, in which the mind continually transcends the body-just as an aircraft overcomes the earth through the sophistication of technology. The Bodies INCorporated spoof calls attention to the Western cultural fixation on property ownership and its protection through cumbersome legal mechanisms. Another theme evident in the artwork is the issue of maintaining personal privacy despite of the skilful data gathering techniques of internet companies.

\subsection{Hybridity}

Besides materiality and embodiment, digital art is also recognized at many levels by hybridity, making the classification of digital art into specific categories challenging and, in some ways, superfluous. Borrowed from the biological sciences, "hybridity" refers broadly to the combination of separate, seemingly unmatched elements into a new, unified form. Although there are many applications of the term, three dimensions are especially pertinent to the digital arts: (a) the blurring of the material and virtual worlds, creating unique "hybrid" realities in which a work is performed, experienced, and preserved; (b) the cross-cutting of categories of artistic practice, dismantling traditional definitions of a creative work of art; and (c) the combining of different media, such as video, animation, and graphic art, into new digital artworks.

In the first sense of the term, hybridity points to our immersion in the physical and virtual worlds through an artwork (Knight 2013). With increasing societal momentum, we are subject to digital/virtual and material/embodied realities at the same time, all the time. In fact, our perceptions and understandings of the physical world (and its bodily or sensory experiences) are gradually related to the impacts of technologies in our daily lives. In relation to this type of hybridity, British artist Joey Holder confronts the problematic separation between the organic and the artificial in her exhibition Digital Baroque (2012). A series of abstract images include analogue paintings alongside digital renderings from biology, natural history, and nanotechnology. For example, the framed digital prints Tunicate \& Running Ants juxtapose the natural, rounded forms of sea and land organisms to the geometrical patterns of hard-edged computer-generated abstractions, calling into question the conceptual divisions we accept as normal and use to classify the world around us (Holder 2012).

In the second sense of hybridity, the distinction between the real and virtual worlds is dismantled when the very format of an exhibition shifts between a conventional gallery space and an online platform. Digital artists interrogate the geographical and temporal constraints of galleries and other exhibition venues; that a viewer must travel to a gallery in a physical location open during set hours limits access to artworks and could be said to promote an elitist viewership. In contrast, many web-based works are available globally, at any time and free of charge, radically transforming the conventions of artistic practice and expanding the criteria used to define artworks. For example, installation artist Kate Steciw's Popular Options (Yellow Diamonds in the Night) (2012) employs Adobe Flash animation to display graphically the most popular Google search terms of 2011. Launched on the website of Klaus Gallery in London, the artwork mirrors the human desire for information and fulfilment in the digital era. Steciw randomizes the sequence of Google search terms as an artistic response to the somewhat anarchic flow of imagery and information on the internet. In its use of an online exhibition space affiliated with a physical gallery, the work demonstrates the hybridity of the digital and the material, in parallel to the hybridity of information flows in online environments (Steciw 2012). That digital artists are often computer programmers or designers suggested a related dimension of hybridity (Lovejoy 2004, 173). Indeed, the pioneers of the digital arts, including mathematician Frieder Nake (b. 1938), software developer Georg 
Nees (b. 1926), and engineer A. Michael Noll (b. 1939), are trained initially as scientists (Rush 2003, 172).

The fusion of different media (e.g., video, sound, text) into a single work marks the third level of hybridity. As the next section goes on explaining, in the 1990s new computer technologies instigate a desire for hybrid art forms. Technological experimentation challenges long-standing divisions between artistic genres. Out of necessity, formal definitions of a creative work begin to shift. Art theorist Darren Tofts attributes this shift to what he calls the "mediascape" and identifies four interrelated fields of practice that comes to be hybridised by digital artists working during this period. These fields are video art, performance art, installation, and animation, all linked by their capacity for hybridity (Tofts 2005, 33). Seminal works from 1990s media art reveal a tendency towards creating hybrid forms. For example, Canadian artist Luc Courchesne's Landscape One (1997) is an interactive video installation producing an immersive virtual environment for participants. Microphones, videodisc players, video projectors, screens, and body detectors are networked together by four computers with touch-plates. A maximum of 12 participants could enter the work at the same time. Video projectors "paint" a single, photo-realistic 360-degree image of the garden landscape of Mount Royal Park in Montreal, Canada, engulfing the participants. Four rear-view projection screens display panoramic views of the garden during different times of day over a 24-hour period (Lovejoy 2004, 172). Installation participants interact with virtual human guides in these projected parkland spaces with each guide possessing specialty knowledge of an area of the virtual garden. People in the park become virtual characters with whom the participants engage (Gagnon 2000). Landscape One combines elements of video, performance, installation, and animation, demonstrating the signature concepts of 1990s art: interaction, interface, and immersion (Tofts 2005, 33).

\subsection{Interactivity}

Like hybridity and other terms outlined thus far, the exact definition of "interactive" has been rendered confusing and, to some extent, meaningless because of its application in a number of seemingly unrelated contexts (Paul 2003, 67). Indeed, digital arts theorists define the term in different ways. In general, "interactive" suggests an audience's ability to manipulate events or alter the artwork. For most theorists, participation and choice are central to the notion. Simply put, interactive artworks necessitate that viewers or spectators become users or participants. Margot Lovejoy defines an artwork as interactive when "the viewer has the power to be an active participant in the unfolding of a work's flow of events, influencing or modifying its form” in which the viewer makes "choices in moving along different paths through the work" (Lovejoy 2004, 167). She offers a lucid explanation of this quite challenging and problematic term:

Interactivity deeply entwines the functions of viewer and artist. In the process, the artist's role changes. This convergence transforms what have been two very different identities of artist and viewer. What interactive art now solicits from the viewer is not simply reception but an independent construction of meaning. In interactively participating, the viewer derives power somewhat parallel with that of the artist: to choose one's own path and discover one's own insights through the interactive work. (Lovejoy 2004, 167)

Crucially, "interactive viewing is completely different from linear activity" (Lovejoy 2004, 165) because interactive works forego the linear narratives of novels or films and instead empower the audience to make choices. Interactive digital artworks depend on the participation and input of multiple users (Paul 2003, 68), who affect the form or meaning of the work not determined or dictated by the artist. Other theorists of digital art define "interactive" according to the varieties of meaning that result from the work as the "complex interplay between contexts and productions of meaning” from the multiple inputs of the artist, viewer, and 
participant in the work (Lovejoy, et al., 2011, 5). The loosely defined genre "interactive art" requires the viewer to take an active part in the artistic process, influencing the creation and manifestation of time-based or process-based works (Simanowski 2011, 120-123).

For the digital arts, the quality of interactivity is the outcome of an ongoing dialogue among the work, artist, and audience members-whether physically present in an exhibition space or virtually online environment. Interactive installations, such as Landscape One, call for the audience to become physically involved - to shape the work-thus transforming the idle spectator or viewer into an engaged participant who makes choices. Therefore, one of the intentions of interactive projects is to provide spaces for creative dialogues to transpire and works to go forward in unanticipated ways. Pivotal to the notion of interactivity is the likelihood of sudden or remote interventions by audience members. As the artist takes a less prominent role, the audience assumes a more significant part in the execution of the work, shifting the traditional balance of power in which an artwork is gazed upon at a distance, and its form more or less is determined by the creator. The digital artist provides the framework or context for the work to emerge through the processes of "exchange, learning, and adaptation” that characterize interactive systems (Lovejoy 2004, 168). While interactive systems are usually participatory, they are infrequently collaborative. The artist nevertheless dictates, to some degree, the form or forum in which the interaction takes place and the meaning which subsequently emerges.

In contrast to interactive media, "non-interactive media" include paintings, photographs, novels, movies, theatre performances, symphonies, and other musical events (Wilson 1993). Critics of interactive media argue that these forms of media, in fact, can be interpreted as participatory. Although the media are fixed (e.g., a novel is recognized as a novel for its specific plot structure and characters), the process of engaging with them can be intensively interactive. The choices of audience members influence their experiences of reading, viewing, or appreciating. Emotional responses, personal memories, and other associations vary enormously. The narrative sequence is not as predetermined as some theorists argue. For example, a book can be started at any page or the flow of a movie can be changed easily by pressing fast forward (Wilson 1993). Another critique of interactivity argues that the degree of interactivity may be a property of the technology rather than the art form and the choices of the artist or audience. New media theorists, such as Lev Manovich, call into question the concept of interactivity specifically in reference to computer art, stating that "a modern computer is an interactive device by definition, so the word does not say anything more than simply that an artwork is using a computer” (Manovich 1996).

\subsection{Narrative}

Another concept explored extensively by digital artists is the narrative. In its simplest form, a narrative is a story with a relatively linear progression of events, experienced when you read a novel, watch a film, or see a play in its entirety. It is suggested that many forms of art make use of narratives, but some do so in more obvious or dramatic ways. A traditional narrative develops according to the structure of a work (e.g., a novel, photography series, or video installation), producing a plot or cohesive sequence of occurrences over time. The author or artist puts characters in a variety of situations, building experience, knowledge, and memory of the narrative in the minds of the audience (e.g., readers, viewers, or participants). Through the believability or compelling nature of the subject matter, an audience becomes immersed in the story, gaining an overall understanding of events imagining a variety of possible conclusions or outcomes. Narrative awareness takes hold when the audience reflects on recollections of previous occurrences whilst continuing to follow the events 
of the story. Hence, every narrative functions according to an "agreement" between the author and the audience (Colson 2007, 84-87).

In understanding the relationship between the digital arts and narratives, we should be aware of how some artistic practices invert the conventional definition of the narrative. Digital artworks - specifically those of the 1990s net.art movement-tend to reconfigure narrative structures, resulting in a "non-linear," randomized, parodic, or open-ended narrative where there is little sense of resolution or closure (Lovejoy 2004, 192-193). As Lovejoy further argues, new media have created a multitude of traditional narrative and non-linear narrative possibilities. "Stories can move front to back, sideways, or up and down, incorporating radically different points in time as the story develops" as multiple threads of a story occur all at once or "embedded features" make it possible for the audience to access other stories (Lovejoy 2004, 192). A "non-linear" narrative requires in a work Tofts' characteristics of interaction, interface, and immersion.

Importantly, rather than narrative being the strongest "pull," symbols and concepts compel an audience to navigate a work, to become immersed and participate as subjects in the production of meaning (Lovejoy 2004, 165). Considering the avatar of Victoria Vesna's Bodies INCorporated discussed earlier in this section, its design demonstrates how the aesthetics of a digital artwork relate intimately to the artist's use of interactive technologies. Non-linear information retrieval systems impact the sequence in which information is conveyed and, thus, disrupted conventional, sequential forms of narrative. For example, hypertext, defined in the 1960s as "non-sequential writing as a text that branches and allows choices to the reader" (Nelson cited in Lovejoy, 2004, 165), leads to the evolution of hypermedia involving images, sound, animation, and other forms of information. Interactive CD-ROMs and DVDs enable users to manipulate images, video, sound, and animations, further showing the impacts of technologies on user choices and the formation of open-ended data networks over fixed narrative structures (Lovejoy 2004, 166).

\subsection{Interface}

Lastly, in this section, the concept of the "interface" is key to the emergence of digital art. A range of artists exploit the technical design and cultural meanings of interfaces, as well as their possibilities and inherent limitations. Familiar interfaces include, for example, television control panels, audio remote controls, telephones, fax machines, and internet browsers. We are surrounded by interfaces in our everyday lives. Christiane Paul defines an interface as a technology that allows a user or viewer to experience an artwork (Paul 2003, 70). She further characterizes an interface, in cybernetic terms, as the point of intersection between humans and machines:

The word interface has become almost synonymous with the navigational methods and devices that allow users to interact with the virtual three-dimensional space of a computer program. Yet, the term has existed for over a century, describing the place at which independent "systems" (such as human/machine) meet and the navigational tool that allows one system to communicate with the other. The interface serves as a navigational device and translator between two parties, making each of them perceptible to the other. (Paul 2003, 70)

In a comparable way, Brenda Laurel defines an interface as "a contact surface,” whereas Donald Norman defines the term in less optimistic language as "an obstacle: It stands between a person and the system being used” (Munster 2006, 117). Lev Manovich argues that a digital artwork is typified by its interfaces to databases containing multimedia material (Paul 2003, 70). For digital artists, an interface proffers a space for improvisation and, as such, is a shifting topography in itself, as Canadian electronic, video, and installation 
artist David Rokeby (b. 1960) explains: "The interface becomes a zone of experience, of multi-dimensional encounter. The language of encounter is initially unclear, but evolves as one explores and experiences" (Munster 2006, 119). The interfaces of various digital artworks "reflect a constantly shifting context that is dependent on the navigational choices we make” (Lovejoy, et al., 2011, 6), further underscoring the notions of interaction and immersion that are key to the digital arts. For example, Rokeby's Very Nervous System (VNS) (1986) employs video cameras, computers, image processors, and audio equipment to create an interface with an ambient environment. Participants produce a suite of sounds through physical interaction with the work (Munster 2006, 118). The focus on bodily experience, sound, and technology in VNS is characteristic of early new media aesthetics. Likewise, Rokeby's Giver of Names (1990) uses a computer connected to a video camera and small projection system to assign names - either meaningful or ridiculous-to objects. When something is placed on the empty pedestal, the computer performs image processing - the results of which are linked to words and ideas, producing a sentence in English spoken by the computer. Through the concept and structure of the interface, Rokeby's installation is a commentary on the logic of new technologies, virtual spaces, and artificial intelligence (Graham 2007, 98).

\section{Art-Historical Contexts}

This section continues the contextual discussion of the digital arts through key art-historical influences. Specifically, the digital arts are indebted to Dada, Fluxus, Conceptualism, and public art (Paul 2003, 11)—all of which trigger new forms of performance, theatre, and installation. These early 20th century to the mid 20th century art movements explore concepts, processes, events, and audience involvement, rather than traditional, material objects of art. In foregrounding the three movements, this section refers to other significant art forms including kinetic, sound, video, and performance art, as well as the techniques of montage, collage, and appropriation. Although outside the scope of this section, the digital arts also reflect some of the ideals of the avant-garde movements Constructivism, Futurism, and Bauhaus, including a fascination with technologies and the aesthetics of machines. In particular, the questioning of the relationship between human societies and technologies is acutely evident in Russian Constructivism's focus on the social function of art and architecture. Moreover, the interconnection among art, technology, culture, and society is a characteristic of the digital arts. Satellite and laser art are precursors to the digital arts that demonstrate this interconnection. In this context, the digital arts have developed out of the interdisciplinary initiatives of the 1960s, prominently Experiments in Art and Technology (EAT), which spans the fields of art, science, and engineering (Graham 2007, 96). Other writers contend that the digital arts have evolved independently of modernist artistic-historical movements and practices and, instead, have "roots not so much in academies of art as in military defense systems" (Rush 1999, 171).

\subsection{Dada}

The digital arts can be traced particularly to the Dada movement (or Dadaism)—established in New York in 1915 and Zurich, Switzerland in 1916, and active internationally throughout the early 20th century. Dada artists react against the social turmoil of World War I, the global appearance of conservative politics in Europe and elsewhere, and the persistence of traditional art practices (Hopkins 2004). Dadaism aims to dissolve the boundaries between different art forms - and between art and the everyday lives of people - through the approaches of collage, photomontage, assemblage, appropriation, and audience participation (Wands 2006, 98). 
Collage is a technique that is central to Dadaism and a number of other art movements (including Futurism and Pop Art) in which an artwork is created by assembling different media or forms (e.g., photographs, painting, texts, sounds, or machines). A related technique is known as montage, used especially in film-making to condense a series of scenes in time (Russian filmmaker Sergei Eisenstein is known as the founder of montage). Dadaists experiments with performance, sound, mail, and telecommunications art, as well as the creation of immersive and interactive environments. Usually regarded as deconstructive and highly conceptual, Dada artworks are also playful, ironic, and politically satirical through their use of a variety of non-traditional techniques. Rather than feverishly random, many Dada projects begin with formal instructions or rules that become central to the process of creating art, resulting in a distinctive "interplay of randomness and control" (Paul 2003, 11).

The Dada combination of order and chance — in terms of our discussion of the digital arts—parallels the algorithms (the codes, instructions, or rules) that make possible the use of computer software by artists and others. Programming as a series of instructions and coding as the rules governing online environments are vital concepts that lend shape to many digital arts projects today. Like their contemporary counterparts, Dadaists exploit communications technologies for conceptual, political, and social commentary. For example, one of the earliest uses of a telegram for artistic reasons occurred in 1919 when Dada artists Richard Huelsenbeck (1892-1974), Joannes Baader (1875-1955), and George Grosz (1893-1959) sent a telegram from Berlin to Milan. The artists addressed the message to the Italian poet and soldier Gabriele D’Annunzio (1863-1938) in response to his participation in the military invasion of the independent Free State of Fiume in present-day Croatia. The telegram read: "Please phone the Club Dada, Berlin, if the allies protest. Conquest a great Dadaist action, and will employ all means to ensure its recognition. The Dadaist world atlas Dadaco already recognizes Fiume as an Italian city” (Kac 2005, 28).

For digital artists, the most influential Dadaist is French-American artist Marcel Duchamp (1887-1968), whose work instigates a broader shift in the art world from pictorial representation to conceptual investigation and audience interaction. Duchamp foregrounds viewer involvement in experimenting with kinetic sculptures producing optical effects. For example, Rotary Glass Plates (Precision Optics) (1920) is a kinetic or moving work consisting of a motor connected by an axis to five panels of glass of different sizes (Knowles 2009, 6). He paints the ends of the glass panels white with black curves to produce an optical illusion of continuous circles when viewed at a distance. Although the work is not "interactive" or "participatory" as defined in the previous section, the kinetic machine mesmerizes an audience with its optical configurations. In 1912, the prestigious Parisian exhibition Paris Salon des Indépendants rejects Duchamp’s Nude Descending a Staircase, a painting which would later be recognized as a classic work of Modernism. Subsequently disenchanted with the very premises of art in modern life, Duchamp begins experimenting with "ready-mades," appropriating ordinary things or "found objects" (e.g., a rack, wheel, or stool) for artistic work. By 1916, Duchamp has produced four ready-mades-Bicycle Wheel, Snow Shovel, Trap, and Hat Rack-leading in 1917 to his most widely recognized found object, Fountain, a porcelain urinal (Cros 2006, 52-53). Ready-mades, such as these, scrutinize the possibility of originality in art and interrogate the hierarchies between manufactured objects and works of art (Cros 2006, 121). Duchamp's ready-mades exhibit concepts of appropriation (the objects are taken from everyday settings) and viewer participation (the full impact of the object relates to the irony and humour of its placement in a formal gallery). As the Mexican poet Octavio Paz comments, "the 'ready-mades' are anonymous objects which the gratuitous gesture of the artist, by the simple act of choosing them, converts into 
'works of art.' At the same time, this gesture dissolves the notion of work. Contradiction is the essence of the act” (Paz 2002, 84).

\subsection{Fluxus}

The Dada phenomenon greatly influences Fluxus - an international group of artists, performers, and musicians working in the 1960s. The key characteristics of Fluxus that we consider here include the interplay of chance and structure, the involvement of an audience in the production of a work, and the dissolving of boundaries between different forms of art. The American Fluxus movement grew in the late 1950s out of experiments in music and education, specifically related to the work of avant-garde composer and teacher John Cage (1912-1992). His compositions often incorporated elements of "found" sound within an overall, prearranged musical structure. Similarly, the European Fluxus scene began in relation to the work of a composer, Karlheinz Stockhausen (1928-2007), who later collaborated with Korean-American artist Name June Paik on early electronic music projects. Reflecting elements of Duchamp's ready-mades in its employment of instructions and chance, Cage's work set the momentum for later precedents in participatory and interactive art (Paul 2003, 13). In New York, Cage and students conducted experiments on chance in music, performance, and poetry, crossing the boundaries between the arts in doing so (Higgins 2002, 1).

Indeed, many Fluxus artworks aim to promote interactions among artists, performers, writers, technicians, and audience members - a transcending of the conventions of art and a significant influence on the digital arts today. Who attend classes with Cage is conceptual artist George Brecht (1926-2008), performance artist Allan Kaprow (1927-2006), and others who would become seminal Fluxus figures and pivotal to the later digital arts trends. Demonstrating Dada principles and Cage's emphasis on randomness, the Fluxus poet Jackson Mac Low (1922-2004), for example, becomes known for writing poetry according to random operations. Some of Low's poems could be read in any direction: left to right, right to left, or top to bottom. Further developing forms of experimentation in relation to chance, Kaprow goes on to coin the term "happening" in Cage's class to refer broadly to multimedia theatre events with some elements of randomness (Higgins 2002, 1-2). Like the Dadaist's use of rules, Fluxus happenings are often based on exact instructions, resulting in the unique combination of chance and predetermination. The Fluxus stress on audience participation during "happenings" is a precursor to the "interactive, event-based nature" of some internet artworks (Paul 2003, 13). In addition to the use of randomness as an artistic principle, Fluxus artists foreground collaboration, participation, and “open-ended" works over modernist principles of individuality and exclusivity in the production of unified art objects (Smith 2005, 123). The Fluxus notion of creative practice as not limited to only one area of the arts effectively dismantls the partitions among music, performance, poetry, and other artforms. Both Dada and Fluxus influence the growth of installation art throughout 1960s and 1980s in response to the artistic, aesthetic, and social constraints of galleries and the "framing" of artworks (Rush 2003, 116).

\subsection{Conceptualism}

Inspired by the ready-mades of Duchamp and the happenings of Fluxus, conceptual art (also known as Conceptualism) emerged as a neo-avant-garde movement in the 1960s and 1970s, particularly in New York City. Referred humorously to as "modernism's nervous breakdown," conceptual art can be defined as art that foregrounds the concepts or ideas in which the work develops over materiality or aesthetic design. Conceptualism opposes the modernist interpretation of art as existing only in painting and sculpture. Instead of 
art as a commodity, conceptualists regard art as a common property (Lovejoy 2004, 58). In 1967, the American artist Sol LeWitt (1928-2007) characterized conceptual art as art built upon reflecting a stable set of ideas:

In conceptual art the idea or concept is the most important aspect of the work... In other forms of art, the concept may be changed in the process of execution... When an artist uses a conceptual form of art, it means that all of the planning and decisions are made beforehand and the execution is a perfunctory affair. The idea becomes the machine that makes the art. (Alberro 2003, 35)

On the whole, conceptual artworks exhibit the qualities of evanescence, irony, satire, and self-reflectiveness. The distinction between an artwork and its contexts (social, cultural, philosophical, political, and so forth) and the division between an artwork and the world are wholly questioned. Conceptual artworks critique the materiality of objects of art, along with visual conventions and assumptions of artistic practices. Alexander Alberro (1999, XVI-XVII) outlines four precursors to the conceptual art movement of the 1960s. The first is the problematising of the traditional object of art in certain modernist practices. Rather than valorizing the aesthetic genius of artists, early conceptualists are interested in all aspects of the work including the technical or manual decisions required to execute the work, as well as the notions or philosophies out of which the work arose. The second precursor is "reductivism," a quality of conventional art based on the limited understanding of artworks as material objects. In contrast, conceptual art prioritizes the processes and concepts leading to and underpinning the artwork. Hence, the viewing of the work is dependent on the context and the numerous intangible elements comprising the work. The third precursor, in Alberro's view, is the negation of formal visual aesthetics, especially evident in Marcel Duchamp's ready-mades in which traditional artistic qualities of beauty, symmetry, balance, harmony, and colour are replaced with the concept and context of the raw found object placed before the viewer. The fourth precursor is reflective self-questioning of avant-garde art movements from the perspectives of artist, subject, and audience about the artistic conventions of the work. Examples of conceptual artworks include Robert Barry's Telepathic Piece (1969) consisting of a chain of thoughts about an artwork communicated to the exhibition by the artist, and Douglas Huebler's exhibition of photographs shot at two-minute intervals while driving (1970).

\subsection{Public Art}

Another key art-historical influence on the emergence of the digital arts is public art—defined as art with social use value that is conceptualized, created for and exists in the public domain. Contemporary public art is developed out of the Russian Constructivists who combine technology and art in anticipation of a new societal structure (Lovejoy 2004, 38). The Constructivists explore theatre, poetry, film, architecture, and other artforms for the social good in the spirit of the Russian Revolution. They employ photo collage as a technique to spread political propaganda. Public art also bears a relationship to Dadaism, Conceptualism, and other avant-garde movements of the 1960s, particularly the "happenings" of Fluxus. Characteristic of public art and its precursors are the subversion of traditional, commercial artforms focused on the production of art objects. In the 1970s, public art gained traction through the postmodernist assertion that meaning results from the numerous contexts (social, political, environmental, theoretical, and so on) of the artwork (Lovejoy 2004, 82).

On the whole, public art engages notions of interactivity and audience participation, outlined in the previous section, and, undeniably, electronic and digital technologies of the last 50 years have expanded the possibilities of public art. As with conceptual art, public art often necessitates extensive artist involvement with the news media to promote the work to the public. The File Room, initiated in 1994 by Catalan-American artist 
Antoni Muntadas (b. 1942), is an example of an ongoing public installation about the history of censorship (www.thefileroom.org). Created collaboratively with a number of physical versions installed in European galleries in the mid-1990s, the work is an online archive of censorship cases dating as far back as the banning of Socrates' books in 387 B.C. Muntadas (n.d.) characterizes the project as "an organic initiative; its shape is ultimately determined by the input of participants." Another example of a public artwork is the billboard-based project Protect Me From What I Want (1986) by American artist Jenny Holzer (b. 1950). Projected over Times Square, New York, the work is a both poetry and installation art.

\subsection{Computer Art}

By the late 1960s, avant-garde artists began involving computers the production of artworks. In addition to Dada, Fluxus and conceptual art-historical influences, the digital arts should be understood in relation to the impact of the personal computer and other military technologies developed by the West during the Cold War. During this period, research funded by military defense departments demonstrated the potential of the computer as a visual medium (Gere 2002, 98). In 1957, the United States National Bureau of Standards developed the first image-processed photo. Begun in 1961, the American defense project known as SAGE contributed to the technological development of graphical interfaces or what we now know as Graphical User Interfaces (GUIs) in collaboration with major computer companies including IBM. These kinds of technological strides, made possible through defense funding and corporate investment, occurred alongside the neo-avant-garde movements of the era, such as conceptual art. Most early digital artists were affiliated with scientific research facilities, prominently Bell Labs (Rush 2003, 176). In the late 1950s and early 1960s, Edward Zajac at Bell Labs experimented with the visualization of data through video generated by computers (Gere 2002, 99). A. Michael Noll, also of Bell Labs, created computer-generated replicas of Mondrian's paintings. Noll's Gaussian Quadratic (1963) series, using algorithms to produce geometric artworks, were exhibited at the Howard Wise Gallery in New York City. Noll's image Computer Composition With Lines (1965) was created on an IBM 7094 digital computer and a General Dynamics SC-4020 microfilm plotter (Gere 2002, 99). By 1965, partly due to the work of Bell Labs artist-scientists, computer replication of visual phenomena reached a significant level (Lovejoy 2004, 173). In 1965, the Wise Gallery and the Galerie Niedlich in Stuttgart, Germany, concurrently hosted the exhibition Computer-Generated Pictures. In 1968, the Museum of Modern Art (MoMA) in New York organized The Machine as Seen at the End of the Mechanical Age, a travelling exhibition of computer-generated art (Blecksmith 2011, 526). During this time, Charles Csuri started developing computer-generated artworks using algorithms, leading to the emergence of computer art as a distinct area of the digital arts. Many conceptual artists also became interested in artificial intelligence, cybernetics, and other theoretical and practical possibilities emerging through computer science (Lovejoy 2004, 180).

\subsection{Satellite and Laser Art}

Throughout the 1970s, artists continued to adopt new technologies to create performances, installations, and other interactive pieces. Two notable trends that emerged during this timeframe are satellite art (or art that makes use of communications objects put in orbit around the earth) and laser art (or kinetic art that uses laser technologies). In his essay “Art and Satellite,” Nam June Paik describes satellite art as a "two-way connection between opposite sides of the earth" that gives "a conversational structure to the art" based on "improvisation, in-determinism, echos, feedbacks, and empty spaces in the Cagean sense.” Moreover, Paik argues that "satellite 
art must make the most of these elements (for they can become strengths or weaknesses), creating a multitemporal, multispatial symphony” (Paik 1996, 435). Since the early 1970s, artists Kit Galloway and Sherrie Rabinowitz have experimented with the use of interactive communications technologies in art. In 1977, the Satellite Arts Project: A Space With No Geographical Boundaries became the first multitemporal, multispatial satellite dance performance (Lovejoy 2004, 232). The interactive work was transmitted between artists on the east and west coasts of the United States (Lovejoy, et al., 2011, 2), resulting in composite video images of dancers on opposite sides of the country. The virtual performance space afforded by the satellite technology gave the participants the impression they could see, hear, and even touch one another as they moved individually in their respective locations (Lovejoy 2004, 232). Like satellite art, laser art brought about an expansion of artforms in the 1960s and 1970s. The term "laser" was an acronym for "light amplification by stimulated emission of radiation.” In the late 1960s, expensive lasers containing krypton gave artists access to a palette of colours to use in performances (Hecht \& Teresi 1998, 233). Nam June Paik became one of the first artists to use lasers after a residency with Bell Labs where the technology was extensively advanced. With laser sculptor Norman Ballard (b. 1950), Paik later created Laser Cone (2001/2010), a large-scale, immersive, and kinetic installation of laser light.

\subsection{Internet Art}

During the 1990s, internet art became the next phase in the evolution of artists using technology. In many ways, internet art spans art, science, engineering, and information in a manner reminiscent of EAT group, founded in 1967 by artist Robert Rauschenberg and scientist Billy Klüver. EAT fostered creative interactions among artists, scientists, and engineers. Indeed, many early internet artists were also computer programmers who worked across the different spaces of the disciplines, demonstrating the bringing together of the arts and technology. Two of the first exhibitions of internet art were Beyond Interface: Net Art and Art on the Net (1998) and Art Entertainment Network (2000) (Graham 2007, 94). In 2000, London-based artist Graham Harwood's Uncomfortable Proximity became the first internet artwork commissioned by the Tate Gallery for its website (www2.tate.org.uk/netart/mongrel/home/default.htm). The artwork appropriated the design of its host, telling a different story about the British art system through the structure and motifs of the Tate's website (Lovejoy, et al., 2011, 6). Through its use of hypertext mark-up language and browser interfaces, Uncomfortable Proximity also questioned the role of digital media in the curation of art (Graham 2007, 95).

\subsection{Art and Technology}

This section concludes on the relationship between the arts and technology. In his essay "The Death of Computer Art” (1996), Lev Manovich divides the digital arts into "Duchamp-land” and "Turing-land,” the latter named after the British mathematician and "father of computer science" Alan Turing (1912-1954). Manovich reflects on what he saw as the impending union between art and computers, evident in many of the movements we have just discussed but reaching a greater intensity during the 1990s. On the one hand, Duchamp-land is the traditional art world of prestigious journals, galleries, and museums, as well as artistic concepts and practices endorsed by them. On the other hand, Turing-land refers to the nascent, circa 1995 computer art world associated with the International Symposium on Electronic Art (ISEA), Ars Electronica, and other high-profile events. Manovich outlines three characteristics of those works admitted to Duchamp-land: They are oriented towards content; they must be appreciated as "complicated" objects situated in larger cultural 
contexts; and, in the postmodernist sense, they exhibit aspects of irony, especially with regard to the materials they use. For Manovich, Paik's work falls into this category because he disrupts the conventions of technology through his ironic subversion of video monitors and laser technology. Some characteristics of works admitted to Turing-land include an attention to the technologies themselves, rather than the content, simplicity and a lack of irony, and a concerted exploration of technology and its limitations. Manovich concludes by stating that "what we should not expect from Turing-land is art which will be accepted in Duchamp-land. Duchamp-land wants art, not research into new aesthetic possibilities of new media. The convergence will not happen” (Manovich 1996). Manovich's argument reflects the broader differences between artists and computer programmers, as observed by digital arts theorists (Lovejoy 2004, 173).

\section{Technological Influences}

Technologies impact artistic practices. Early 20th century French poet Paul Valéry anticipated the ascendency of the digital arts when he commented that "we must expect great innovations to transform the entire technique of the arts, thereby affecting artistic invention itself and perhaps even bringing about an amazing change in our very notion of art” (Lovejoy 2004, 1). This section considers Valéry's claim. Key technological trends have influenced the development of the digital arts. New digital devices and software presently enable artists to experiment with the possibilities of art, combining technical proficiency and "artistic invention" in the process. However, the innovative application of technologies by artists has also catalyzed developments in the technologies themselves (Rush 1999, 178). This includes the history of television, video, computers, internet, software, and social media. Indeed, during the "digital revolution" of the 1990s, computer technologies became more and more commonplace (Lovejoy, et al., 2011, 2).

Early technological contexts for the digital arts include the prominent telecommunications mediums of television and video. In the 1950s, television became a "visual cultural phenomenon," exceeding the influence of print media (books, newspapers, magazines), radio, and cinema (Lovejoy 2004, 78). Decades earlier, in 1873, the history of television began with the discovery of the "photoconductive" capacity of selenium. This scientific breakthrough made possible for the first time the concepts of "seeing by electricity" sending moving images electronically between locations. Late 19th century scientists, such as Alexander Graham Bell, experimented with transmitting pictures through wires. By 1926, the Scottish electrical engineer John Logie Baird demonstrated a simple form of television in London, and in 1927 American inventor Philo Farnsworth produced the first television set. In 1936, the first high-definition broadcasting system was made public in the UK, followed by comparable developments in Japan, the USSR, USA, France, and Germany. In 1939, the cathode ray tube became the main component of television sets (Rush 2003, 14). By 1960, 90\% of American households had television. Electronic video for recording, duplicating, and broadcasting moving images grew in the 1950s and 1960s, especially with the appearance of the Portapak, the first portable video camera and recorder, released by Sony in 1967. This technological advance promoted access to video as a creative medium, leading to the work of Wolf Vostell and Name June Paik.

Computers have revolutionized art. The artist-programmer hybrid is now a common phenomenon. The computer is ever more an instrument for "high speed visual thinking” in art (Lovejoy 2004, 170). However, computers are part of the broader, intermeshed history of science and technology that has impacted the trajectory of the digital arts (Paul 2003, 8). This history includes technologies developed at military, academic, and commercial research centers and eventually exported to consumers around the world. The foundations for 
the modern computer were put down in 1801 when French merchant Joseph Marie Jacquard (1752-1834) demonstrated the Jacquard loom. His mechanical loom used a chain of punched cards to control the process of textile manufacturing. In 1834, English inventor Charles Babbage (1791-1871) designed the "analytical engine,” a hand-operated device for performing calculations (Wands 2006, 20). Later on, in 1946, the University of Pennsylvania produced the first digital computer, known as ENIAC (Electronic Numerical Integrator and Computer) (Rush 1999, 176). Before the mid-1900s, all computers were analogue. In 1951, UNIVAC was patented as the first computer designed for a commercial market.

In the late 1940s, American mathematician Claude Shannon (1916-2001) discovered that the algebraic logic developed by English mathematician George Boole (1815-1864) could be used to construct a data storage device. Boolean logic became the foundation for the digital computer. To appreciate the difference between digital and analogue computers is to understand the practices of counting and measuring what we refer to as “calculating” (Youngblood 1970, 183). “To compute” literally means to calculate. There are two forms of calculating: measuring and counting. On the one hand, a measuring device is based on an analogue process because it makes an "analogous" comparison between a quantity and a number that represents the quantity. For example, a speedometer measures a speed by assigning a number: $100 \mathrm{kms}$ travelled at that rate of travel over an hour. On the other hand, a counting machine is digital because it uses "two-way switches" to express quantities directly as digits or units of the binary system (Youngblood 1970, 183). The binary system uses the number two as its base, just as the decimal system uses 10. The binary code of digital computers is expressed as variations of the numbers one and zero, underlying functions such as on or off, yes or no, voltage or no voltage. A series of binary switches then relay voltages. The "bit" as the basic unit of digital information is the contraction of "binary digit" (Youngblood 1970, 183).

Before the appearance of the PC in the 1980s, computers were expensive, specialist technologies. Except for a few pioneering practitioners affiliated with research centers like Bell Labs, most artists were not seriously engaging the creative possibilities of computers as tools or mediums. The situation started to change as computer technology became more accessible through a number of advances. In 1968, American engineer Douglas Engelbart (1925-2013) of the Stanford Research Institute conceived of bitmapping, windows, and the computer mouse. The process of bitmapping enabled the electrical pulses in a computer's processor to be reflected in an image on the display. The "on" or "off" state of the electrical pulses corresponded, as mentioned above, to binaries of $1 \mathrm{~s}$ and 0 s. Small units of computer memory were assigned to the pixels of a computer screen. These concepts underpined the GUI (Graphical User Interface), as well as the desktop and windows interfaces pioneered by Apple's Macintosh computers and, later, the Microsoft Windows operating systems of PCs (personal computers) (Paul 2003, 10-11). In 1980 and 1981, manufacturers, such as Hewlett-Packard, began to make PCs commercially available to the public. Time magazine selected the PC as the "Man of the Year" in 1982, a role usually reserved for international leaders (Swedin \& Ferro 2005, 96). In 1984, the Apple Macintosh was branded the "computer for the rest of us," indicating a trend towards the democratization of technology and data. Rather than the awkward MS-DOS text commands of the PC, the Mac employed user-friendly and more intuitive icons, menus, and a mouse. Reflecting the relationship between embodiment and technology in the computer age, the mouse became an extension of the user's hand.

Developments in the digital arts also are indebted to advances in computer software, defined as programs that control the processor of a computer, allowing the execution of certain functions. Lev Manovich argues that artists use two kinds of software: "data searchable structures" and "algorithms." The first results in 
"hypernarratives" without beginning and end in which the artist navigates a pathway through a database (defined as a software program) of items presented non-hierarchically. The second negotiates the "hidden logic" of algorithms, as evident in the creation of "gamelike objects" (Lovejoy 2004, 163). In the early 1970s, artists such as German artist Manfred Mohr (b. 1938) and American artist-programmer Duane Palyka began devising special software to suit their creative imperatives (Lovejoy 2004, 173). Similarly, pioneers of computer music German-American composer Herbert Brün (1918-2000) and American composer Lejaren Hiller (1924-1994) developed compositional software specific to their musical aims. Hiller co-authored the program MUSICOMP to automate certain aspects of composition. Under the tutelage of Hiller, Brün learnt the programming language FORTRAN, producing computer-generated works Infraudibles (1968) and Mutatis Mutandis (1968) (Holmes 2008, 255). Their software anticipated the appearance of the synthesiser (Rush 1999, 178). In the world of digital photography, image manipulation software has also been crucial. While photography has always been marked by some degree of manipulation, software developments have triggered an explosion in the scope and impact of these processes. As early as 1987, Thomas Knoll began writing an image processing program called Display, later evolving into the editing software Adobe Photoshop as we know it today. Photoshop and other image applications have transformed the practice of photography.

The internet has played an indispensable role in the genealogy of the digital arts. In 1945, American engineer and inventor Vannevar Bush (1890-1974) proposed the idea of the Memex, an analogue device that would allow users to browse books, serials, and images on microfilm. Although it was never constructed, the concept of the Memex prefigured the internet as a universally available database of digitally networked content (Paul 2003, 8-9). A decade later, the United States Department of Defense founded ARPA (Advanced Research Projects Agency) in 1957 to advance the exploration of Cold War technologies. By the late 1960s, ARPANET matured into a data network having no central authority, safeguarding American military information from loss, or hacking. In 1963, American sociologist Theodor Holm Nelson (b. 1937) coined the terms "hypertext" and "hypermedia" to refer to hyperlinked writing and reading environments in which the dynamic interplayed among text, images, and video and audio allowing the user to select a personal pathway through the data (Paul 2003, 10). Hyperlinks made it possible for users to shift easily among areas of content that, in an analogue context, would be accessed only in the physical domain of books, shelves, cities, and countries (Lovejoy, et al., 2011, 3).

The dawning of Web 2.0 in the year 2000 called for social media to "nurture connections, build communities, and advance democracy" through technology or, in other words, to create a more social Web (Van Dijck 2013, 4). The latest technological frontier for the digital arts is the emergence of social media, exemplified by LinkedIn (2003), Facebook (2004), Flickr (2004), Myspace (2003), Twitter (2006), YouTube (2005), and Wikipedia (2001). Social media necessitates a number of internet applications, including podcasting and streaming "on-demand" video or audio, developed in the 1990s. A podcast refers to audio, video, or textual content downloaded on a subscription basis to a mobile device or computer. British journalist Ben Hammersley proposed the term "podcasting” in The Guardian newspaper in 2004 as a contraction of "pod" and "broadcasting." Also in 2004, Liberated Syndication developed the first podcast hosting service. Internet Transmission Control Protocol (TCP), originating in the work of American computer scientists Vint Cerf and Bob Kahn in the 1970s, facilitates the transfer of content over the internet. Other technologies, such as the serial port microphone allowing users to record audio and the MP3 as the universal standard for audio files, underpin podcasting. Ideas of interaction, participation, and democratization characterize social media as a 
“tool” or "medium” for creating new possibilities in the digital arts. Just how artists will engage with social media technologies is becoming evident at this very moment.

\section{Conclusion}

The digital arts cross among the arts, the sciences, and technology. This paper has discussed the key theoretical, art-historical, and technological contexts of the digital arts. Common terms for describing digital art practices, including materiality, embodiment, hybridity, interactivity, and narrativity, have been outlined, along with the chief differences between analogue and digital media. The crucial distinction between technology as a tool and medium has been explored. The digital arts reflect core tenets of Postmodernism and Poststructuralism, including the emphasis on context and interpretation. Materiality encompasses the physical properties and form of a digital artwork as it changes over time. Digital artists, such as Stelarc, probe issues of embodiment, raising questions about human relationships to new technologies and virtual environments. Hybridity describes the fusion of the material and virtual world, the cross-cutting of conventions of artistic practice, and the use of different media (e.g., television, video, satellite) in a single work. Dada, Fluxus, Conceptualism, and public art are among the prominent influences on the emergence of internet and computer-based art in the 1990s. The development of television, video, computer, internet, and social media technologies has impacted and will continue to influence the trajectory of the digital arts.

\section{Works Cited}

Alberro, Alexander. "Reconsidering Conceptual Art, 1966-1977.” Conceptual Art: A Critical Anthology. Cambridge, MA: The MIT Press, 1999. XVI-XXXVII.

Alberro, Alexander. Conceptual Art and the Politics of Publicity. Cambridge, MA: MIT Press, 2003.

Blecksmith, Anne. “Computer Imaging.” Joan Marter, ed.. The Grove Encyclopedia of American Art. New York: Oxford University Press, 2011. 526-7.

Bodies INCorporated. "Welcome to Bodies INCorporated." <http://www.bodiesinc.ucla.edu/welcome.html>.

Colson, Richard. The Fundamentals of Digital Art. Lausanne: AVA Academia, 2007.

Cros, Caroline. Marcel Duchamp. London: Reaktion Books, 2006.

Gagnon, Jean. "Luc Courchesne: Landscape One.” <www.fondation-langlois.org/html/e/page.php?NumPage=127> .

Gere, Caroline. Digital Culture. London: Reaktion Books, 2002.

Graham, Beryl. "Redefining Digital Art: Disrupting Borders.” Fiona Cameron \& Sarah Kenderdine, eds.. Theorizing Digital Cultural Heritage: A Critical Discourse. Cambridge: The MIT Press, 2007. 93-112.

Hecht, Jeff \& Teresi, Dick. Laser: Light of a Million Uses. Toronto: General Publishing Company, 1998.

Higgins, Hannah. Fluxus Experience. Berkeley: University of California Press, 2002.

Holder, Joey. "Digital Baroque.” <www.joeyholder.com/digital-baroque-documentation/>.

Holmes, Thom. Electronic and Experimental Music: Technology, Music and Culture, 3 ed.. New York: Routledge, 2008.

Hopkins, David. Dada and Surrealism: A Very Short Introduction. Oxford: Oxford University Press, 2004.

Janson, Horst Woldemar. History of Art: The Western Tradition, 6 ed.. Upper Saddle River: Pearson Education, 2004.

Kac, Eduardo. Telepresence \& Bio Art: Networking Humans, Rabbits \& Robots. Ann Arbor: University of Michigan Press, 2005.

Knight, Amy. "Hybridity in New Art: Split Life and Augmented Reality in Six New Art Works." <http://www.dazeddigital.com/blog/article/15085/1/hybridity-in-new-art>.

Knowles, Kim. A Cinematic Artist: The Films of Man Ray. Bern: Peter Lang, 2009.

Leonardi, Paul. "Materiality, Sociomateriality, and Socio-Technical Systems: What Do These Terms Mean? How Are They Different? Do We Need Them?” Paul Leonardi, Bonnie Nardi \& Jannis Kallinikos, eds., Materiality and Organizing: Social Interaction in a Technological World. New York: Oxford University Press, 2012. 25-48.

Lovejoy, Margot. Digital Currents: Art in the Electronic Age. New York: Routledge, 2004. 
Lovejoy, Margot, Paul, Christiane, \& Vesna, Victoria. “Introduction.” Context Providers: Conditions of Meaning in Media Arts. Bristol: Intellect, 2011. 1-10.

Manovich, Lev. "Subject: The Death of Computer Art." <http://www.manovich.net/TEXT/death.html>.

Manovich, Lev. The Language of New Media. Cambridge: MIT Press, 2001.

Manovich, Lev. Soft Cinema: Navigating the Database. Cambridge, MA: MIT Press, 2005.

Mitra, Partha \& Bokil, Hemant. Observed Brain Dynamics. Oxford, UK: Oxford University Press, 2008.

Munster, Anna. Materializing New Media: Embodiment in Information Aesthetics. Lebanon, NH: Dartmouth College Press, 2006. Muntadas, Antoni. “The File Room.” <http://www.thefileroom.org/>.

Paik, Nam June. “Art and Satellite.” Theories and Documents of Contemporary Art: A Sourcebook of Artists’ Writings. Berkeley, CA: University of California Press, 1996. 434-6.

Paul, Christiane. Digital Art. London: Thames \& Hudson, 2003.

Paul, Christiane. “Contextual Networks: Data, Identity, and Collective Production.” Context Providers: Conditions of Meaning in Media Arts. Bristol: Intellect, 2011. 103-22.

Paz, Octavio. “The Ready-Made.” Joseph Masheck, rd.. Marcel Duchamp in Perspective: Writings on Duchamp by Jasper Johns, Donald Judd, Clement Greenberg, John Cage, Octavio Paz, \& Others. Cambridge, MA: Da Capo Press, 2002. 84-89.

Rush, Michael. New Media in Late 20th-Century Art. London: Thames \& Hudson, 1999.

Rush, Michael. Video Art. London: Thames \& Hudson, 2003.

Scott, Jill \& Bisig, Daniel. “Art and Science Research: Active Contexts and Discourses.” Margot Lovejoy, Christiane Paul \& Victoria Vesna, eds.. Context Providers: Conditions of Meaning in Media Arts. Bristol: Intellect, 2011. 299-328.

Simanowski, Roberto. Digital Art and Meaning: Reading Kinetic Poetry, Text Machines, Mapping Art, and Interactive Installations. Minneapolis: University of Minnesota Press, 2011.

Smith, Owen. "Fluxus Praxis: An Exploration of Connections, Creativity, and Community." Annemarie Chandler \& Norie Neumark, eds.. At a Distance: Precursors to Art and Activism on the Internet. Cambridge: Massachusetts Institute of Technology, 2005. 116-38.

Steciw, Kate. "Popular Options (Yellow Diamonds in the Light)." <www.katesteciw.com/index.php?/popular-options-2012/>.

Stelarc \& Smith, Marquard. “Animating Bodies, Mobilizing Technologies: Stelarc in Conversation.” Stelarc: The Monograph. Cambridge, MA: MIT Press, 2005. 214-41.

Stiles, Kristine \& Shanken, Edward. "Missing in Action: Agency and Meaning in Interactive Art.” Margot Lovejoy, Christiane Paul \& Victoria Vesna, eds.. Context Providers: Conditions of Meaning in Media Arts. Bristol: Intellect, 2011. 31-54.

Swedin, Eric \& Ferro, David. Computers: The Life of a Technology. Baltimore: The Johns Hopkins University Press, 2005.

Tofts, Darren. Interzone: Media Arts in Australia. Fishermans Bend: Craftsman House, 2005.

Van Dijck, José. The Culture of Connectivity: A Critical History of Social Media. Oxford: Oxford University Press, 2013.

Wands, Bruce. Art of the Digital Age. New York: Thames \& Hudson, 2006.

Wiener, Norbert. Cybernetics, or, Control and Communication in the Animal and the Machine, 2 ed.. Cambridge, MA: MIT Press, 1961.

Wilson, Stephen. "The Aesthetics and Practice of Designing Interactive Computer Events." $<$ http://userwww.sfsu.edu/swilson/papers/interactive2.html>.

Youngblood, Gene. Expanded Cinema. Boston: Dutton, 1970. 